\title{
Erratum: Epigenetic regulation of Ifng expression
}

Charalampos G Spilianakis \& Richard A Flavell

Nat. Immun. 8, 681-683 (2007); published online 19 June 2007; corrected after print 22 June 2007

In the version of this News \& Views initially published, the figure credit is missing. This figure should be credited to Ann Thomson. The error has been corrected in the HTML and PDF versions of the article.

Corrigendum: Comprehensive epigenetic profiling identifies multiple distal regulatory elements directing transcription of the gene encoding interferon- $\gamma$

Jamie R Schoenborn, Michael O Dorschner, Masayuki Sekimata, Deanna M Santer, Maria Shnyreva, David R Fitzpatrick, John A Stamatoyonnapoulos \& Christopher B Wilson

Nat. Immun. 8, 732-742 (2007); published online 3 June 2007; corrected after print 5 July 2007

In the version of this article initially published, the surname of the penultimate author is misspelled. The correct spelling is Stamatoyannopoulos. The error has been corrected in the HTML and PDF versions of the article. 